\title{
Mental Health Service Needs among Chinese Urban Residents: Intensity and Factors
}

\author{
Xiao-Gang Wang ${ }^{1,2}$, Ming-Chun $\mathrm{Luo}^{3} \&$ Xi-Hua Qiu ${ }^{4}$ \\ ${ }^{1}$ Judicial and Police Officers Professional College, Deyang, China \\ ${ }^{2}$ School of Psychology, Southwest University, Chongqing, China \\ ${ }^{3}$ School of Education, Yunnan University of Nationalities, Kunming, China \\ ${ }^{4}$ Chongqing Branch of Municipal Public Security Bureau, Chongqing, China \\ Correspondence: Xiao-Gang Wang, Judicial and Police Officers Professional College, Deyang, 618000, China. \\ Tel: 86-838-251-4182. E-mail: xiaogangwang2011@163.com
}

$\begin{array}{lrr}\text { Received: December 20, } 2011 & \text { Accepted: March 31,2012 Published: June 1, } 2012 \\ \text { doi:10.5539/ijps.v4n2p253 } & \text { URL: http://dx.doi.org/10.5539/ijps.v4n2p253 }\end{array}$

\begin{abstract}
The continued growth of mental health service has raised concerns about mental health service needs (MHSN) among Chinese urban residents. This exploratory survey uses a national sample from 35 communities of 30 cities covering all ranks of economics status in China, measured as the intensity and pattern of MHSN. The intensity of MHSN reported by respondents is moderate; it is significantly related to race, household income, residence and education. Implications for policy makers and services professionals are discussed to better Chinese mental health services.
\end{abstract}

Keywords: mental health service, mental health service needs, urban resident, china

\section{Introduction}

With a claim to shift from service-driven to needs-led pattern of MHS delivery (Lightfoot, 1995), the focus also shift from predicators of service use to predicators of service need (Wright, Williams, Wilkinson, 1998). A number of developed countries have embarked on the quest to understand population mental health needs, and have introduced the needs-led philosophy into the process of decision-making (Andrews, Hall, Teesson, 1999; Commonwealth Department or Health and Aged care, 1999; Evans, Greenhalgh, \& Connelly, 2000). Most attention toward Chinese MHS is still laid on the service delivery, however, little has been done to discover needs for MHS in China, whether in the city or in the country.

There are marked differences between the various countries with regard to the feature of service need. Rickwood et al classified help-seeking as informal (family and friends) and formal help-seeking (mental health professionals, social workers, etc.) (Rickwood, Deane, Wilson, \& Ciarrochi, 2005). Collectivistic people have more negative help-seeking attitude than individualistic people, and prefer informal help as mainstream help and formal help as the last choice. (Tata \& Leong, 1995; Lin, 2002) In China, some of those who need MHS also seek help from barefoot doctors and necromancy. However, these choices of service are not included in western need assessments.

Although the importance of obtaining accurate need for MHS is well accepted, the optimal methods to achieve it are controversial. In China, Luo (2010) developed the Mental Health Services Needs Questionnaire (MHSNQ) based on the Chinese sample to obtain the need information. This scale is developed through the process of theoretical reflection and analysis, interviews, repeated factor analysis and the unspecific attempts to increase internal consistency and factor loadings among college students and migrant workers. In their studies, mental health services need (MHSN) refer to the willingness for MHS based on individual' desired mental health states. Given the dearth of empirical work on MHSN in China, this study is conducted to learn more about MHSN among urban residents.

\section{Methods}

\subsection{Sample}

The initial 2400 questionnaires were sent to the potential participants by 35 trained research fellows from two 
universities. Finally, as a result of missing data the available sample $(n=1983)$ comprised of 1017 male and 962 female, including 1261 Han and 717 ethnic minority. Nearly three fourth $(60 \%)$ of the samples had completed Secondary (high) school, elementary school level accounted for $12.71 \%$, illiterates accounted for $4.34 \%$ and $35.10 \%$ were college graduates. The average age of this sample was 33.77 years $(\mathrm{SD}=13.01$, range $=10-82$ years).

\subsection{Questionnaire}

Mental Health Services Needs Questionnaire of Urban-community version (MHSNQU) was revised from MHSNQ, which is a reliable and valid assessment of needs examined by a series of previous studies. MHSNQU has 47 items organized into 5 dimensions: service attitude, service organization, service provider, service content, and service approach. In this study, participants responded on a 4-point: " $1=$ not at all", " $2=$ rarely", " $3=$ sometimes", or " $4=$ often".

\subsection{Procedure}

The survey used for this research was developed in several steps. First, select representativeness of the obtained sample. 10 provinces almost covered all ranks of economics status (undeveloped area, developing area, developed area, see http://www.mof.gov.cn/) were chosen, and then three cities (the capital city and two randomly chosen cities in each province were selected. One or two neighborhoods communities in one city randomly were chosen. Second, we recruited research fellows via study advertisements posted in two universities. The potential research fellows contacted the research staff and determined whether they met any of the following criteria: (1) major is psychology or education; (2) residence belonged to these cities. Eligible candidates provided his or her telephone and residence information. A total of 35 research fellows were selected from the eligible candidates the two Universities. The final research fellows were collectively trained in two universities. Third, respondents were randomly selected from each community based on house number, and agreed to accomplish the questionnaire. Research fellows would read items and choices, and assist practitioners when they were illiterate, or could not complete questionnaires for bad eyesight or other physical problems. The initial 2400 questionnaires were distributed to 35 communities, resulting in a return rate of $82.63 \%$.

\section{Results}

One-sample Kolmogorov-Smirnov test on the score of MHSNQ showed that this data was Normal distribution $(\mathrm{Z}=2.494, \mathrm{p}=.000)$. The score of $53.29 \%(1052)$ was over Mean $(\mathrm{M}=121.78, \mathrm{SD}=20.37)$. Scores of $85.66 \%$ respondents (1691) were over 101.41 (M-SD), higher than the score by selecting all the choice of 'rarely' (scored 94). These findings display that the intensity MHSN reported by respondents is moderate.

Analysis of variance (ANOVA) found that there were significant differences in term of race, household income, residence, and education in MHSN, whereas there were not any differences in term of age and gender. Racial differences existed on service organization $\left(F_{(1,1974)}=87.56, p<.001\right)$, service provider $\left(F_{(1,1975,)}=101.89, p\right.$ $<.001)$, and service approach $\left(F_{(1,1972)}=14.49, p<.001\right)$, as well as $\operatorname{MHSNQU}\left(F_{(1,1967)}=44.48, p<.001\right)$. Need scores of ethnic minorities were higher than Han on previous aspects.

The difference of household income was found on service organization $(\mathrm{F}(2,1969)=3.49, \mathrm{p}<.05)$, service content $\left(F_{(2,1970)}=5.77, p<.01\right)$, and service approach $\left(F_{(1,1967)}=8.79, p<.001\right)$, as well as MHSNQU $\left(F_{(2}\right.$, $\left.{ }_{1962)}=4.16, p<.05\right)$. LSD t-test showed that the score of high-incomers was significantly higher than moderate-incomers regarding service organization $(p<.05)$; low-incomers' mean score was lowest in service content; and high-incomer's mean score was highest in service approach.

There was a significant residence differences in service attitude $\left(F_{(2,1977)}=5.45, \mathrm{p}<.01\right)$, service organization $(F$ $(2,1976)=67.10, p<.001)$, service provider $\left(F_{(2,1977)}=79.82, p<.001\right)$ and service approach $\left(F_{(2,1974)}=18.31, p\right.$ $<.001)$, as well as MHSNQU $\left(F_{(2,1969)}=40.25, p<.001\right)$. Undeveloped area had significantly higher score than the other two areas on previous aspects $(p<.001)$, judging by LSD test, and developing areas was higher than developed areas in respects of service organization $(p<.01)$, service provider $(p<.001)$ and MHSNQU $(p<.05)$. In sum, respondents with high-income reported higher scores than other income levels, but the need intensity perceived by residents in undeveloped areas was stronger than developing areas followed by developed areas.

Finally, the differences of degree levels also existed on the scores of service organization $\left(F_{(3,1967)}=15.69, p\right.$ $<.001)$, service provider $\left(F_{(3,1968)}=34.12, p<.001\right)$, and MHSNQU $\left(F_{(3,1960)}=8.00, p<.001\right)$. The scores of college graduates were significantly lower than other levels on service organization $(p<.001)$, service provider $(p<.001)$ and MHSNQU, and the scores of secondary school degree was lower than both elementary school degree and illiteracy on service organization, service provider, and MHSNQU. In other words, these findings indicated the trend: the higher degree level respondents had, the lower need level they perceived. 


\section{Discussions}

This investigation appears to be the first to provide descriptive information regarding MHSN in Chinese urban residents, respectively diversified and clarified the information of MHSN by standardized measures. Findings about intensity of MHSN among respondents provide important implications for both future research and policy making.

In the current study, it was found that the score of $85 \%$ respondents was higher than the score (94) of selecting the choice of "rarely" on all items, indicating that most urban residents "sometimes or often" needed MHS. In other words, urban residents have moderate MHSN level based on the finding from different aspects of the MHSNQU. Previous studies, which investigated police, prison police, and urban resident, found a higher percentage of individuals reporting some need for MHS (Huang, Zheng, Luo, Su, \& Chen, 2011; Luo, 2010; Zhang, 2010; Zong, Huang, Wang, \& Zhang, 2009). In Chinese perspectives, the proposed objects of need are not only themselves but also their family and relatives, and the proposed contents of need are not only mental health disorders (e.g., substance abuse, psychiatric illness, social adaption) but also employment and children education ( $\mathrm{Li}$, Ma, Ang, \& Xu, 2005). Additionally, prevalence of mental problems also affected MHSN perceived by people. Zhang (2010) promulgated the new research data that the number of mental illness was 17.3 million in China. Urbanization is a stressful process which may lead to mental illness, and the rate of urban population with psychosocial problems was 20\% reported by Chinese National Mental Health Survey in 2007.

In this sample of urban residents, the effect of race, household income, residence and education on MHSN was investigated, whereas not any difference in term of age or gender was found. Research has considered a wide and diverse range of factors that may affect need for MHS. Yet, little consensus has been achieved despite considerable research in this area. People have diverse understanding of MHSN in diverse countries, and the unified theory and the consistency in the measurement of NHSN do not exist.

Ethnic minorities were found to have higher MHSN than Han ethnicity. The difference may be attributed to lack of service resources and higher occurrence of mental problems among minorities. In Chinese cities, most minorities in urban residents are migrants from their original residence. Migration is a stressful process that may lead to mental illness (Bhugra \& Jones, 2001). Mental health status of minorities is under the average level. Additionally, the lack of specific culture-orientated MHS may lead to underutilization of mental services among minorities compared to Han. These factors may lead to more unmet need among ethnic minorities.

Need scores was much higher among respondents with high-income. It is commonly for individuals with higher socioeconomic status to have the greater prevalence of perceived need care (Katz, Kessler, Frank, Leaf, \& Lin, 1997). Moreover, the analysis reveals that economic development is inversely related with need. The service resources may play an important role. The developed area with better economy is more likely to support mental health service. Additionally, the developed area is the first place where modern mental health theories, therapies and policies were introduced with more investments. As a typical sample of developed area, Shanghai is the first city that enacted their mental health law, and gradually constructed mental health centers in community. Relatively sufficient resource and supportive policy can better meet MHSN among common people.

It was found that the higher academic degree respondents got the lower need scores they perceived, which was consistent with previous survey (Zong et al., 2009). As we known, urbanization is a hundred flowers bloom in China with thousands and millions of people flooded into cities. Individuals less educated tend to encounter higher risk of jobless, discrimination and other life pressures. Many studies also reported that lower education was significant correlated with high occurrence of mental problems.

\section{Implications for Behavioral Health}

Our findings indicate there is an enormous need for MHS reported by urban residents. Seeking MHS is not the same as receiving appropriate treatment and not everyone requires specialist's treatment. Mrazek and Haggerty (2010) brought forward mental health intervention spectrum that included three service levels: prevention, treatment, and maintenance. The public approach to mental health should include health promotion and disease prevention, Therefore, policy-makers and providers of MHS system need to integrate resources of government, professionals, private and voluntary organizations and individuals, working together to provide multiple-level service meeting various need of individuals, not only treatment service and pharmacological interventions, but also service of prevention, rehabilitation and development. As resources are limited in China, multiple-level MHS spectrum may increase the likelihood to avoid unnecessary jams that people would like to wait outside some specialists' offices, help them receive appropriate service matching their need, as well as maximize the efficiency of MHS resources. 


\section{References}

Andrews, G., Hall, W., Teesson, M., \& Henderson, S. (1999). The mental health of Australians: National survey of mental health \& well-being report No 2. Canberra: Mental Health Branch, Commonwealth Department of Aged Care.

Bhugra, D., \& Jones, P. (2001). Migration and mental illness. Advances in Psychiatric Treatment, 7, $216-222$. http://dx.doi.org/10.1192/apt.7.3.216

Chinese Psychological Society and Institute of Psychology. (2007). Mental health status of Chinese. Retrieved from http://psydb.psych.ac.cn/kycg.htm

Commonwealth Department or Health and Aged care. (1999). Mental health information development: National information priorities and strategies under the second national mental health plan 1998-2003. Canberra: Commonwealth of Australia.

Evans, S., Greenhalgh, J., \& Connelly, J. (2000). Selecting a mental health needs assessment scale: guidance on the critical appraisal of standardized measures. Journal of Evaluation in Clinical Practice, 6(4), 379-393. http://dx.doi.org/10.1046/j.1365-2753.2000.00269.x

Huang, X., Zheng, Y., Luo, M., Su, D., \& Chen, B. (2011). Assessing of the Chinese college students mental health services needs. Journal of Southwest University (Social Sciences Edition), 37(2), 6-11.

Katz, S. J., Kessler, R. C., Frank, R. G., Leaf, P., \& Lin, E. (1997). Mental health care use, morbidity, and socioeconomic status in the United States and Ontario. Inquiry, 34(1), 38-49.

Li, C., Ma, B., Ang, Q., \& Xu, H. (2005). Cross-sectional survey of mental health service status and demand police population in Shanghai (in Chinese). Chinese Journal of Health Psychology, 13(5), 350-353.

Lightfoot, J. (1995). Identifying needs and setting priorities: Issues of theory, policy and practice. Health and Social Care in the Community, 3(2), 105-114. http://dx.doi.org/10.1111/j.1365-2524.1995.tb00011.x

Lin, Y. N. (2002). Taiwanese university students' perspectives on helping. Counseling Psychology Quarterly, 15(1), 47-48. http://dx.doi.org/10.1080/09515070110104015

Luo, M. (2010). The present status of mental health service needs in Chinese youth and teenage. Unpublished Doctorial Dissertation. Chongqing: Southwest University.

Mrazek, P. J., \& Haggerty, R. J. (2010). Reducing risk for mental disorders: Frontiers for preventive. In: B. L. Levin, K. Hennessy, \& J. Petrila (Eds.), Mental health services: A public health perspective (3rd Ed.). (pp. 355-356). New York: Oxford University Press.

Rickwood, D., Deane, F. P., Wilson, C. J., \& Ciarrochi, J. (2005). Young people's help-seeking for mental health problems. Australian e-Journal for the Advancement of Mental Health, 4, 1-34.

Tata, S. P., \& Leong, F. (1994). Individualism-collectivism, social-network orientation, and acculturation as predictors of attitudes toward seeking professional psychological help among Chinese Americans. Journal of Counseling Psychology, 41, 280-287. http://dx.doi.org/10.1037/0022-0167.41.3.280

Wright, J., Williams, R., \& Wilkinson, J. R. (1998). Development and importance of health needs assessment. British Medical Journal, 316, 1310-1313. http://dx.doi.org/10.1136/bmj.316.7140.1310

Zhang, D. (2010). Study on mental and constitution health of national minority college. Guizhou Ethnic Studies, 31(3), 165-169.

Zong, Y., Huang, T., Wang, X., \& Zhang, Q. (2009). A primary exploration to the psychological services needs of police officials working in prisons and institutions of reeducation in certain province. China Journal of Health Psychology, 17(3), 266-267. 